\title{
EFFECTS OF PRECURSORS ON KITASAMYCIN PRODUCTION IN Streptomyces kitasatoensis
}

\author{
EFEITOS DOS PRECURSORES NA PRODUÇÃO DE KITASAMICINA EM \\ Streptomyces kitasatoensis
}

\author{
Xiong ZHENG ${ }^{1}$; Ruifang YE ${ }^{1}$; Fengxian $\mathrm{HU}^{1}$; Quangui MAO $^{2}$; Hongzhou ZHANG ${ }^{2}$ \\ 1. The State Key Laboratory of Bioreactor Engineering, East China University of Science \\ and Technology, Shanghai, China; 2. Topfond Pharmaceutical Co., Ltd., Henan, China. rfye@ecust.edu.cn
}

\begin{abstract}
To improve kitasamycin biosynthesis by Streptomyces kitasatoensis Z-7, the addition of two precursors, sodium acetate and ethyl acetate, to the fermentation medium was evaluated. Ethyl acetate was the most effective precursor compared with control conditions; In a 15-L fermentor, the kitasamycin titer was $21 \%$ higher when $0.48 \%$ ethyl acetate was added compared to control conditions. Content of the $\mathrm{A}_{5}$ component increased by $5.1 \%$, and the $\mathrm{A}_{4}$ content decreased slightly compared to that of the control. During kitasamycin synthesis, intracellular and extracellular concentrations of acetic acid were higher for S. kitasatoensis Z-7 supplemented with ethyl acetate than for the non-supplemented strain, and the activities of acyl-CoA synthetases, acyl-phosphotransferases, and acyl-kinases were also significantly increased, suggesting that increased acetyl-CoA levels can explain the high kitasamycin titer. These findings may improve the industrialscale production of kitasamycin for clinical use, and the addition of $0.48 \%$ ethyl acetate as precursors in the medium at the beginning of cultivation was a new method to mitigate the negative influence on the cell growth of excess precursor.
\end{abstract}

KEYWORDS: Streptomyces kitasatoensis. Ethylacetate. Fermentation. Component. Kitasamycin

\section{INTRODUCTION}

Kitasamycin, also referred to as leucomycin, is a 16-membered polyketide macrolide antibiotic produced by Streptomyces kitasatoensis that is widely used as a broad-spectrum antibiotic in medical applications (HATA et al., 1953; VANDERHAEGHE; HOOGMARTENS, 1993). Kitasamycin is a multi-component antibiotic containing $\mathrm{A}_{9}, \mathrm{~A}_{8}, \mathrm{~A}_{7}, \mathrm{~A}_{6}, \mathrm{~A}_{5}, \mathrm{~A}_{4}, \mathrm{~A}_{1}, \mathrm{~A}_{3}$, and $\mathrm{A}_{13}$ (WOODWARD, 1957). The components exhibit structural differences in the acyl substituent at position $\mathrm{C}-4$ " of the mycarose moiety and the alternation of a hydroxyl and an acetyl group at C-3 of the 16-membered lactone ring (VÉZINA et al., 1979). Its structure is described in the literature (ZHENG; GAO, 2015). $\mathrm{A}_{1} / \mathrm{A}_{3}, \mathrm{~A}_{4} / \mathrm{A}_{5}, \mathrm{~A}_{6} / \mathrm{A}_{7}$, $\mathrm{A}_{8} / \mathrm{A}_{9}, \mathrm{~A}_{13}$ were very similar in structure, in each pair, the hydroxylated member is more active than its acetylated partner at C-3 of the 16-membered lactone ring. According to the Chinese Pharmacopoeia (2015 Edition), the main components of kitasamycin shall not total less than $85 \%, \mathrm{~A}_{5}$ should comprise $35 \%-70 \%, \mathrm{~A}_{4}$ should comprise 5\%-25\%. Among kitasamycin components, $\mathrm{A}_{5}$ is the most clinically potent, with a butyryl group at position 4" $\left(\mathrm{R}_{2}\right)$ (VANDERHAEGHE; HOOGMARTENS, 1993). Polyketides are assembled using several common biosynthetic precursors including acetyl-CoA, malonyl-CoA, and methylmalonyl-CoA (CHAN et al., 2009). The biosynthesis of the polyketide antibiotic kitasamycin, which consists of a 16membered branched lactonic ring, requires five acetates, one propionate, one butyrate, and another unidentified two-carbon precursor (OMURA et al., 1975). Polymerization of activated acyl units to form the macrolide lactone ring is catalyzed by polyketide synthases in microorganisms by a mechanism similar to that utilized in fatty acid synthesis (HOPWOOD, 1997). Khaoua et al. (1992) showed that short-chain fatty acids increase spiramycin production by Streptomyces ambofaciens when cultivated on dextrins and ammonium chloride.

Based on these previous studies, short-chain fatty acids have the potential to increase kitasamycin titers. In general, the direct addition of these substances to the fermentation medium not only changes the medium $\mathrm{pH}$ but also influences the cell growth (ROYCE et al., 2013; TAN et al., 2016). Therefore, more research focusing on the addition of salt precursors, such as sodium acetate, sodium butyrate, and precursor analogs, to promote the biosynthesis of kitasamycin is needed, including analyses of the effects of excess precursor at the beginning of fermentation on cell growth. Ethyl acetate can mitigate this influence; similar to 
soybean oil, it has almost no effect on the cell growth. Ethyl acetate decomposes slowly, thereby minimizing the influence of excess precursor on the cell growth.

In the current study, the influence of precursor on the biosynthesis of kitasamycin and its components was further investigated by analyses of intracellular and extracellular short-chain fatty acids. At the enzymatic level, two enzyme systems were used to supply acetyl-CoA to form 16membered lactone rings, i.e., an acyl-CoA synthetase system and an acyl-kinase system coupled with acyl-phosphotransferases.

\section{MATERIAL AND METHODS}

\section{Microorganism and chemicals}

S. kitasatoensis Z-7, a producer of kitasamycin, was obtained from Topfond Pharmaceutical Co., Ltd. (Henan, China). Sodium acetate, ethyl acetate and all other analytical-grade chemicals were from Meryer (Shanghai) Chemical Technology Co., Ltd. (Shanghai, China).

\section{Culture conditions in 250-mL Erlenmeyer flasks}

The seed medium contained the following (per liter): starch (20 g), cooked soybean meal (15 $\mathrm{g})$, peptone $(5 \mathrm{~g})$, yeast extract $(5 \mathrm{~g})$, glucose $(10 \mathrm{~g})$, $\left(\mathrm{NH}_{4}\right)_{2} \mathrm{SO}_{4}(2.5 \mathrm{~g}), \mathrm{KH}_{2} \mathrm{PO}_{4}(0.2 \mathrm{~g}), \mathrm{NaCl}(4 \mathrm{~g})$, $\mathrm{MgSO}_{4}(0.25 \mathrm{~g}), \mathrm{CaCO}_{3}(3 \mathrm{~g}), \mathrm{pH}$ 7.3.

The fermentation medium contained the following (per liter): starch (25 g), cooked soybean meal $(25 \mathrm{~g})$, glucose $(10 \mathrm{~g})$, silk fibroin powder (11 g), $\mathrm{NH}_{4} \mathrm{Cl}(2 \mathrm{~g}), \mathrm{KH}_{2} \mathrm{PO}_{4}(0.7 \mathrm{~g}), \mathrm{ZnSO}_{4}(0.06 \mathrm{~g})$, $\mathrm{MnCl}_{2}(0.5 \mathrm{~g}), \mathrm{CaCO}_{3}(3 \mathrm{~g})$, soybean oil $(40 \mathrm{~mL})$, $\mathrm{pH}$ 7.3.

The mycelia of $S$. kitasatoensis were maintained in a $25 \%$ glycerol solution at $-20^{\circ} \mathrm{C}$. Then, $1 \mathrm{~mL}$ of the mycelia solution was inoculated into a $250-\mathrm{mL}$ flask containing $40 \mathrm{~mL}$ of seed medium and cultivated at $28^{\circ} \mathrm{C}$ for $24 \mathrm{~h}$. Then, $1 \mathrm{~mL}$ of the resulting seed culture was transferred to a $250-\mathrm{mL}$ flask containing $25 \mathrm{~mL}$ of the desired fermentation medium and cultivated at $28^{\circ} \mathrm{C}$ for 112 $\mathrm{h}$. All cultivations were performed on a rotatory shaker at $220 \mathrm{rpm}$.

\section{Culture conditions in a 15- $\mathrm{L}$ fermentor}

Preliminary seed medium contained the following (per liter): starch (20 g), cooked soybean meal (15 g), nitrogen ammonia powder $(5 \mathrm{~g})$, yeast extract $(3 \mathrm{~g})$, glucose $(10 \mathrm{~g}),\left(\mathrm{NH}_{4}\right)_{2} \mathrm{SO}_{4}(2.5 \mathrm{~g})$, $\mathrm{KH}_{2} \mathrm{PO}_{4}(0.2 \mathrm{~g}), \mathrm{NaCl}(4 \mathrm{~g}), \mathrm{MgSO}_{4}(0.25 \mathrm{~g}), \mathrm{CaCO}_{3}$ $(3 \mathrm{~g})$, soybean oil $(5 \mathrm{~mL}), \mathrm{pH} 7.1$.
The secondary seed medium contained the following (per liter): starch (20 g), cooked soybean meal (25 g), silk fibroin powder (7 g), glucose (15 $\mathrm{g}$ ), amylase (0.015 g), $\mathrm{ZnSO}_{4}(0.06 \mathrm{~g}), \mathrm{MnCl}_{2}(0.5$ $\mathrm{g}), \mathrm{CaCO}_{3}(2.5 \mathrm{~g})$, soybean oil $(6 \mathrm{~mL}), \mathrm{pH}$ 7.1.

The fermentation medium contained the following (per liter): starch (18 g), cooked soybean meal (20 g), glucose (10 g), silk fibroin powder (7 $\mathrm{g})$, amylase $(0.03 \mathrm{~g}), \mathrm{NH}_{4} \mathrm{Cl}(1.5 \mathrm{~g}), \mathrm{KH}_{2} \mathrm{PO}_{4}(0.7 \mathrm{~g})$, $\mathrm{ZnSO}_{4}(0.06 \mathrm{~g}), \mathrm{MnCl}_{2}(0.5 \mathrm{~g}), \mathrm{CaCO}_{3}(3 \mathrm{~g})$, soybean oil $(30 \mathrm{~g})$, antifoam agent $(0.2 \mathrm{~mL}), \mathrm{pH} 7.3$.

The mycelia solution $(1 \mathrm{~mL})$ was inoculated into a 250-mL flask containing $40 \mathrm{~mL}$ of preliminary seed medium and cultivated at $28^{\circ} \mathrm{C}$ for $26 \mathrm{~h} .2 .5 \mathrm{~mL}$ of this preliminary seed culture was transferred to a $500-\mathrm{mL}$ flask containing $50 \mathrm{~mL}$ of the secondary seed medium and cultivated at $28^{\circ} \mathrm{C}$ for $17 \mathrm{~h}$. Finally, $1 \mathrm{~L}$ of the secondary seed culture was inoculated into a 15 -L fermentor containing 10 $\mathrm{L}$ of fermentation medium and cultivated at $28^{\circ} \mathrm{C}$ for $112 \mathrm{~h}$.

For the final fermentation, the dissolved oxygen concentration was controlled at $25-40 \%$ of air saturation by adjusting the agitation at 400$600 \mathrm{rpm}$, and the $\mathrm{pH}$ was not controlled during the fermentation process. During the fermentation period, when the packed mycelia volume (PMV) was higher than $30 \%$, a small amount of sterile water was added to the fermentor.

\section{Fermentative parameter detection}

PMV was calculated as the volume of precipitate/fermentation broth (CHEN et al., 2013). Total sugar and reducing sugar levels in the broth were assayed by the Fehling method and amino nitrogen levels were estimated by the formaldehyde titration method. The total protein in the culture supernatant was measured by the Bradford protein assay.

\section{Assay of organic acids}

To determine the intracellular and extracellular organic acids (acetic acid, butyric acid) affecting metabolism, the Shimadzu highperformance liquid chromatography system (LC20AT; Kyoto, Japan) was used with a differential refractive index detector (RID-20A) and a Carbomix H-NP $(10 \mu \mathrm{m}, 7.8 \times 250 \mathrm{~mm})$ column. The flow rate was $0.6 \mathrm{~mL} / \mathrm{min}$ and the mobile phase was a 2.5 $\mathrm{mM} \mathrm{H} \mathrm{H}_{2} \mathrm{SO}_{4}$ solution. The column was operated at $55^{\circ} \mathrm{C}$.

\section{Kitasamycin titer and component assay}

The biological titer was determined by the conventional disc method using Bacillus subtilis as 
the test microorganism and a kitasamycin standard obtained from Topfond Pharmaceutical Co., Ltd. (Henan, China). The components of kitasamycin were determined using an HPLC system (Agilent 1260 Infinity; Agilent Technologies, Santa Clara, CA, USA), using a CAPCELL PAK $\mathrm{C}_{18}$ MGII column $(150 \mathrm{~mm} \times 4.6 \mathrm{~mm}, 5 \mu \mathrm{m})$ with a mobile phase mixture of $0.1 \mathrm{~mol} / \mathrm{L}$ ammonium acetate $(\mathrm{pH}$ 4.5), methanol, and acetonitrile (40:55:5, v/v/v). The detection wavelength was $231 \mathrm{~nm}$ and the flow rate was $1 \mathrm{~mL} / \mathrm{min}$. The column was operated at $60^{\circ} \mathrm{C}$.

\section{Preparation of cell extracts}

Mycelia were collected at various times by centrifugation at $10,626 \times g$ at $4^{\circ} \mathrm{C}$ and washed with $20 \mathrm{mM}$ Tris-HCl buffer ( $\mathrm{pH} 8.0$ ) containing $100 \mathrm{mM}$ $\mathrm{NaCl}$. The mycelia were resuspended in a minimal volume of the same buffer and sonicated for 30 cycles with a working period of $3 \mathrm{~s}$ in each cycle of $6 \mathrm{~s}$ at $300 \mathrm{~W}$ in an ice water bath using a sonicator (model JY92-II; Scientz Co., Ningbo, China). After cell lysis, the extract was centrifuged for $10 \mathrm{~min}$ at $10,626 \times g$ and $4^{\circ} \mathrm{C}$ to remove cell debris. The supernatant was used to determine enzyme activity and protein concentrations.

\section{Enzyme assay}

Acyl-CoA synthetase (AS) activity, acylkinase (AK) activity, and acyl phosphotransferase (APT) activity were assayed as described by Zeng et al. (2016). One unit (U) of enzymatic activity was defined as the amount of enzyme that catalyzed the formation of $1 \mu \mathrm{mol}$ of each enzymatic reaction product per hour under the abovementioned conditions. The specific enzymatic activity is expressed in terms of $\mathrm{U} / \mathrm{mg}$ of protein.

\section{Statistical analysis}

Each experiment was performed in triplicate and the data are presented as the mean \pm standard deviation (SD).

\section{RESULTS AND DISCUSSION}

\section{Influence of precursors on kitasamycin titers in shake flasks}

The effects on kitasamycin titers of adding to two precursors (sodium acetate and ethyl acetate) to the fermentation medium were examined. Each precursor was added to the culture medium at various concentrations at the beginning of cultivation. As shown in Table 1, the kitasamycin titer increased as the sodium acetate concentration increased in a certain concentration range. However, according to statistical analysis, the kitasamycin titer $(11764 \pm 351 \mathrm{U} / \mathrm{mL})$ was merely $6.2 \%$ higher when $0.15 \%$ sodium acetate was added compared to control conditions $(11077 \pm 273 \mathrm{U} / \mathrm{mL})$. Its effect on the kitasamycin titer was not significant, i.e., although sodium acetate was beneficial for kitasamycin biosynthesis, excess precursor also influenced the cell growth in the early phases (Figure 1).

Table 1. Effects of sodium acetate at various concentrations on the kitasamycin titer

$\begin{array}{llllll}\text { Concentration }(\%) & \text { Control } & 0.05 & 0.1 & 0.15 & 0.2\end{array}$

Titer $(\mathrm{U} / \mathrm{mL})$

$11077 \pm 273$

$11220 \pm 252$

$11435 \pm 231$

$11764 \pm 351$

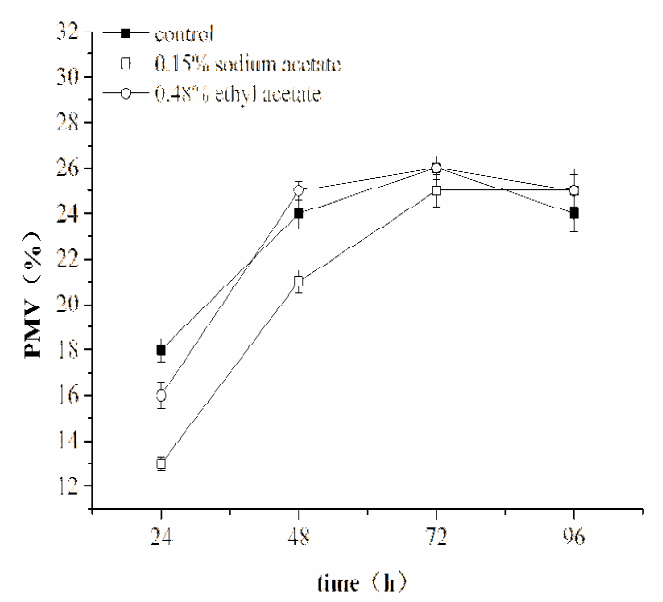

Figure 1. Effects of $0.15 \%$ sodium acetate and $0.48 \%$ ethyl acetate at various time $(24 \mathrm{~h} 、 48 \mathrm{~h} 、 72 \mathrm{~h} 、 96 \mathrm{~h})$ on PMV in shake flasks. Sodium acetate ( $\square$ ), ethyl acetate (०) and control (ロ). 
Various concentrations of ethyl acetate were added to the fermentation medium $(0.32 \%, 0.48 \%$, $0.64 \%, 0.8 \%$, and $0.96 \%$ ) to determine the optimum initial ethyl acetate concentration for maximizing kitasamycin titers. The results are summarized in Table 2. The highest kitasamycin titer, 12,758 $\mathrm{U} / \mathrm{mL}$, was obtained using an initial ethyl acetate concentration of $0.48 \%$, which resulted in an increase in kitasamycin biosynthesis by $S$. kitasatoensis Z-7 of approximately $18.8 \%$ compared with biosynthesis in the control conditions (i.e., no precursor added). A high concentration of ethyl acetate did not inhibit the biosynthesis of kitasamycin in a certain concentration range, and the favorable effect of ethyl acetate on kitasamycin titer did not further improve for ethyl acetate concentrations above $0.64 \%$. This asymptote in titer can be explained by the lack of other short-chain fatty acids related to lactonic ring construction or restricted metabolic flux.

Table 2. Effects of ethyl acetate at various concentrations on the kitasamycin titer

\begin{tabular}{ccccccc}
\hline Concentration (\%) & Control & $\mathbf{0 . 3 2}$ & $\mathbf{0 . 4 8}$ & $\mathbf{0 . 6 4}$ & $\mathbf{0 . 8}$ & $\mathbf{0 . 9 6}$ \\
\hline Titer $(\mathrm{U} / \mathrm{mL})$ & $10734 \pm$ & $11633 \pm$ & $12758 \pm$ & $11994 \pm$ & $12407 \pm$ & $12242 \pm$ \\
& 307 & 324 & 357 & 454 & 423 & 242 \\
\hline
\end{tabular}

These results indicate that ethyl acetate is better than sodium acetate for enhancement of kitasamycin production by $S$. kitasatoensis Z-7. Kitasamycin synthesis was not enhanced by addition of sodium acetate to the medium, which influenced the cell growth of S. kitasatoensis Z-7. Ethyl acetate had almost no effect on cell growth (Figure 1), it was slowly decomposed during the process of fermentation, minimizing the potential influence of excess precursor on S. kitasatoensis Z-7.

\section{Influence of ethyl acetate on kitasamycin titers and components in a $15-\mathrm{L}$ fermentor}

To further investigate the effect of ethyl acetate on the biosynthesis of kitasamycin, fermentation experiments were performed in a $15-\mathrm{L}$ fermentor. When ethyl acetate was added, the kitasamycin titer was $10546 \mathrm{U} / \mathrm{mL}$ at $102 \mathrm{~h}$, which was $21 \%$ higher than that of the control (Figure 2).

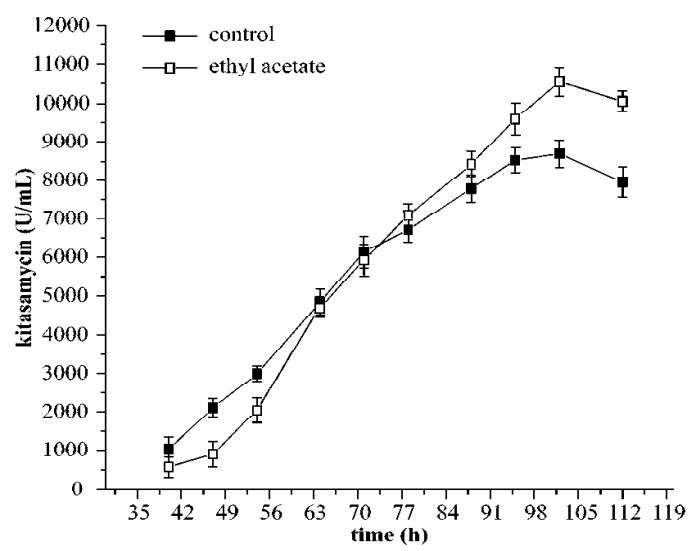

Figure 2. Effects of ethyl acetate on kitasamycin titers in a 15-L fermentor. Ethyl acetate ( $\square$ ) and control (匹).

When the kitasamycin titer reached its maximum, the content of the $\mathrm{A}_{5}$ component was $5.1 \%$ higher for medium with ethyl acetate than for the control. The content of the $\mathrm{A}_{4}$ component was slightly lower for medium with ethyl acetate than the control (Figure 3).

The 3-acetylated $\mathrm{A}_{4}$ component is derived from its 3-hydroxylated partner $\mathrm{A}_{5}$. It has been speculated that C-3 acetylation is repressed by butyrate (KITAO et al., 1979). After $78 \mathrm{~h}$, the concentrations of intracellular and extracellular butyric acid were higher with ethyl acetate than without ethyl acetate during kitasamycin biosynthesis (Figure 4). These data suggest that ethyl acetate plays a significant role in increasing the $\mathrm{A}_{5}$ content and reducing the conversion of $\mathrm{A}_{5}$ to $\mathrm{A}_{4}$. 


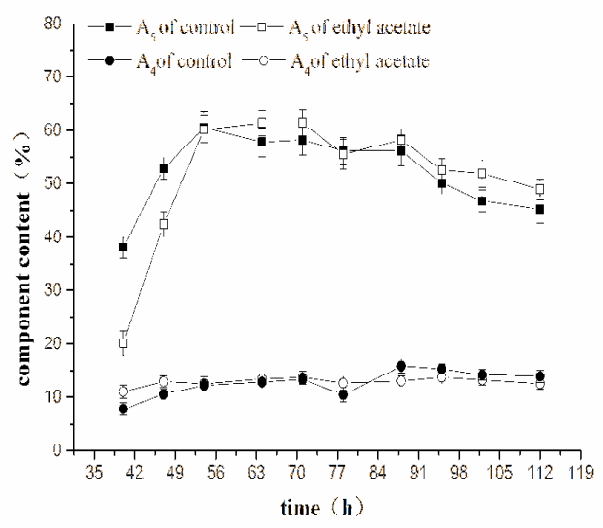

Figure 3. Time course analysis of components upon addition of ethyl acetate in a 15-L fermentor. Ethyl acetate $(\square, \circ)$ and control
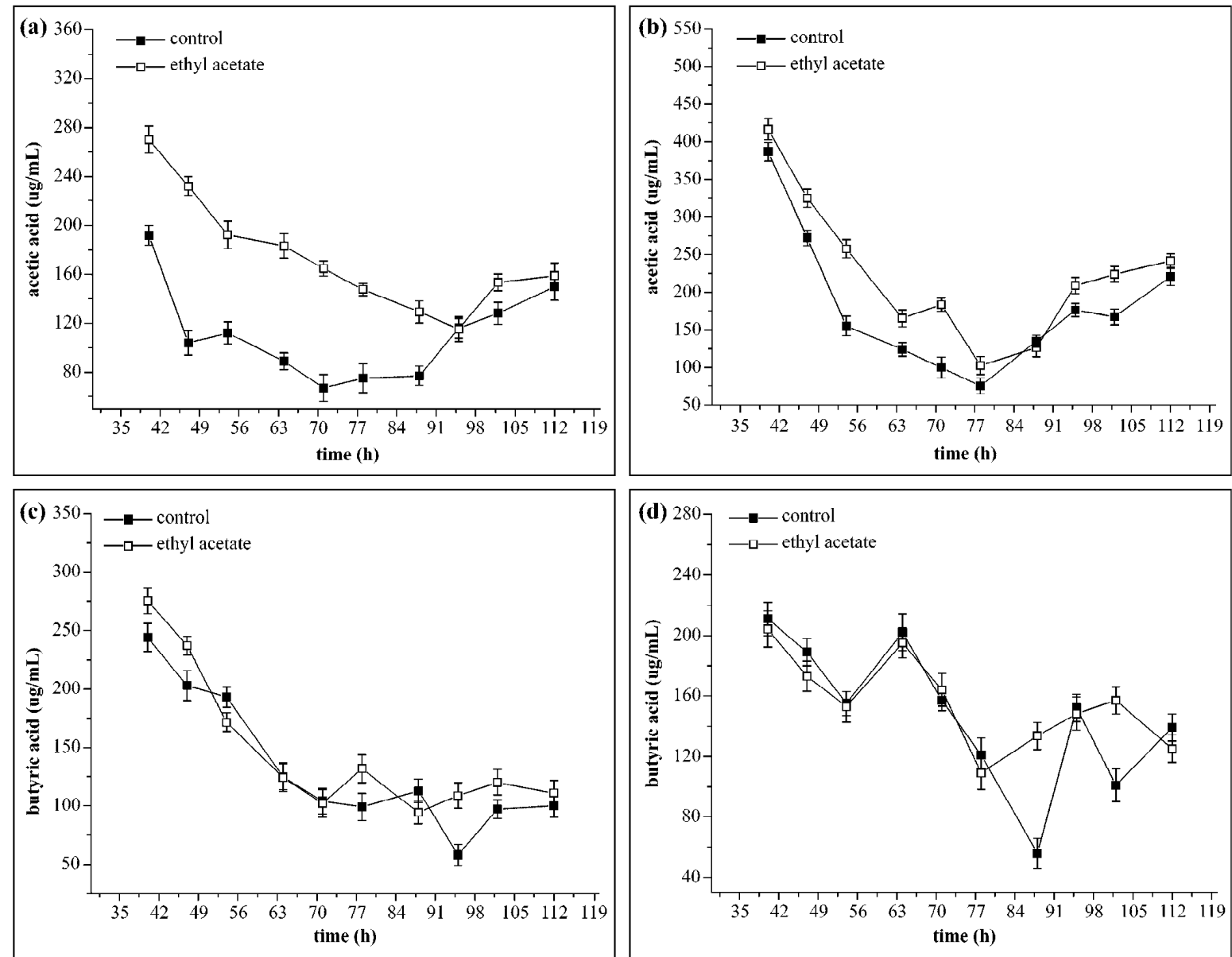

Figure 4. Time course analyses of intracellular organic acid (a, c) and extracellular organic acid (b, d) levels with and without the addition of ethyl acetate in a 15-L fermentor. Ethyl acetate ( $\square$ ) and control ( $\square$ ).

\section{Effects of ethyl acetate on fermentation parameters}

The PMV in the fermentor with ethyl acetate was lower than that in the control conditions within $78 \mathrm{~h}$, but then increased sharply and was higher than that of the control. These results indicate that addition of ethyl acetate at an early stage had a negative effect on cell growth; as ethyl acetate was slowly broken down and consumed, the negative effects gradually weakened. After the PMV reached 
approximately $30 \%$, it declined rapidly owing to the addition of sterile water. In the early phase of fermentation, the $\mathrm{pH}$ value for both treatments began to increase; after $54 \mathrm{~h}$, the $\mathrm{pH}$ decreased rapidly because soybean oil began to rapidly decompose, producing various acidic materials. The minimum $\mathrm{pH}$ values were observed at $112 \mathrm{~h}$ when ethyl acetate was added to the medium $(\mathrm{pH} 4.62)$ and at $95 \mathrm{~h}$ without ethyl acetate ( $\mathrm{pH} 4.97)$ (Figure 5).

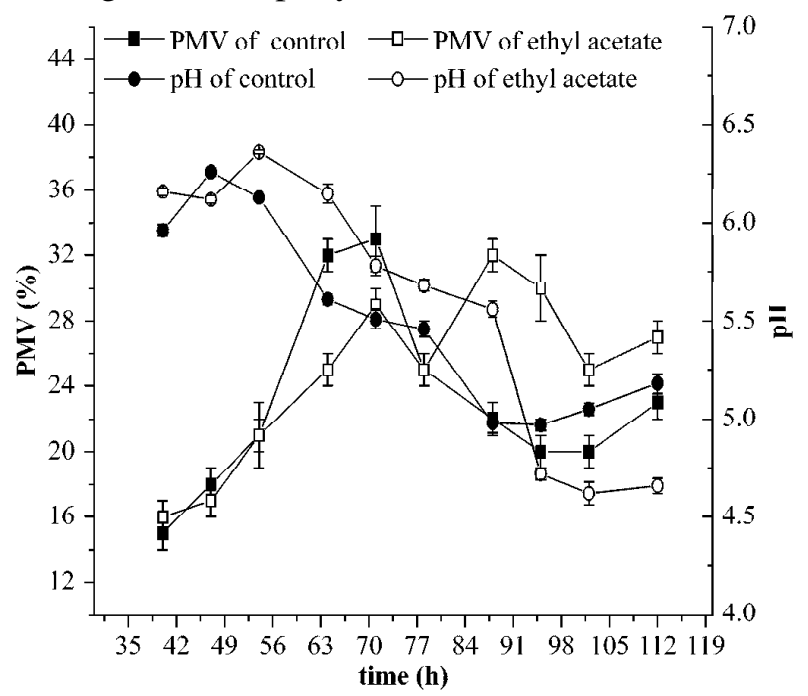

Figure 5. Effects of ethyl acetate on PMV and pH in a 15-L fermentor. Ethyl acetate $(\square, \circ)$ and control ( $\mathbf{\square}, \bullet)$.

When ethyl acetate was added to the medium, the residual amino nitrogen, total sugar, and reducing sugar contents were obviously higher than those of the control at early time points. These results indicate that at the early stage, ethyl acetate had an effect on the metabolic capability of $S$. kitasatoensis $Z-7$, in accordance with the reduction in the PMV.
Amino nitrogen was rapidly consumed in both conditions during the biosynthesis of kitasamycin. From 40 to $102 \mathrm{~h}$, the consumption rate with the addition of ethyl acetate was 17.4 $\mathrm{mg} / \mathrm{L} \cdot \mathrm{h}$, which was higher than that of the control $(0.6 \mathrm{mg} / \mathrm{L} \cdot \mathrm{h})$. However, at $102 \mathrm{~h}$, amino nitrogen content did not differ significantly between conditions (Figure 6(a)).

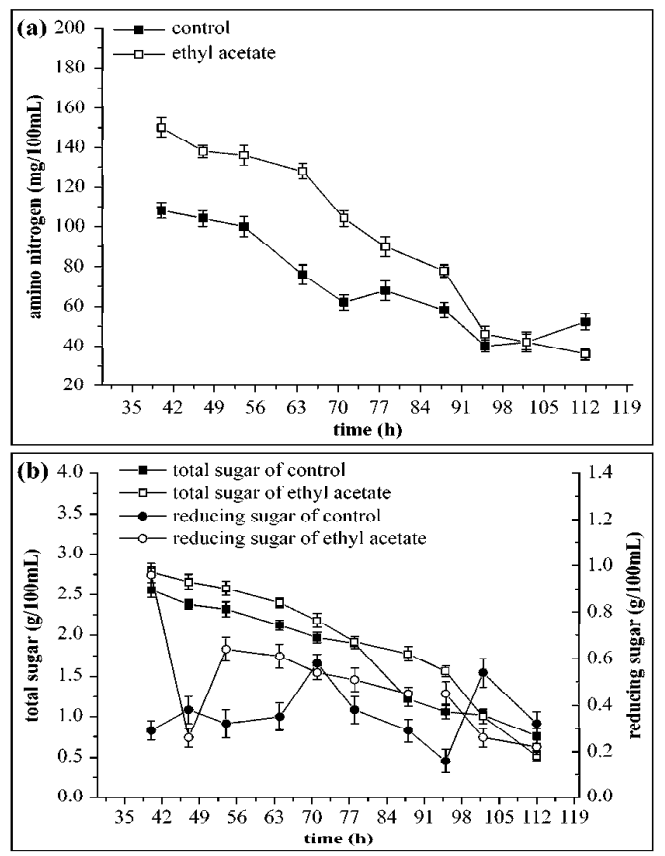

Figure 6. Time course analysis of amino nitrogen (a), reducing sugar, and total sugar (b) upon addition of ethyl acetate in a 15-L fermentor. Ethyl acetate $(\square, 0)$ and control 
Time course analyses of total sugar and reducing sugar are summarized in Figure 6(b). From 40 to $102 \mathrm{~h}$, total sugar was continuously consumed in both cases, and the rate of consumption of total sugar was $0.36 \mathrm{~g} / \mathrm{L} \cdot \mathrm{h}$, which was obviously higher than that observed in the control condition (0.29 $\mathrm{g} / \mathrm{L} \cdot \mathrm{h})$. From 40 to $47 \mathrm{~h}$, reducing sugar was rapidly consumed with the addition of ethyl acetate; however, the reducing sugar content was only 0.26 $\mathrm{g} / 100 \mathrm{~mL}$ at $40 \mathrm{~h}$ in the control condition. The consumption of reducing sugar occurred comparatively later with addition of ethyl acetate than in the control conditions. When the reducing sugar content is too low, starch decomposition provides the reducing sugar in the fermentation process, enabling cell growth. Accordingly, the reducing sugar content was maintained in a certain range in both conditions in the production phase.

\section{Changes in organic acid content in a 15-L fermentor}

Short-chain fatty acids are precursors in the biosynthesis of kitasamycin; accordingly, they may explain the higher kitasamycin titer observed in the ethyl acetate treatment compared to the control and clarify the role of ethyl acetate in kitasamycin biosynthesis, as shown in Figure 4(a) and Figure 4(b). After addition of ethyl acetate, the increase in kitasamycin production corresponded with higher intracellular and extracellular acetic acid concentrations compared to the control. These results indicate that more acetic acid accumulated as a raw material for kitasamycin lactone ring biosynthesis. After $78 \mathrm{~h}$, acetic acid levels began to increase, probably owing to the reduced demand for acetic acid, the decomposition of ethyl acetate, and the utilization of soybean oil. From $78 \mathrm{~h}$ to $102 \mathrm{~h}$, the accumulation of intracellular and extracellular butyric acid was higher for the ethyl acetate treatment than in the control, and the observed increase in butyric acid content repressed C-3 acetylation, reducing conversion of $\mathrm{A}_{5}$ to $\mathrm{A}_{4}$. Two peaks for extracellular butyric acid were detected at $64 \mathrm{~h}$ and 95-102 h for both conditions (Figure 4(c) and Figure 4(d)).

The accumulation of short-chain fatty acids was directly associated with biosynthesis of kitasamycin. In summary, the accumulation of intracellular and extracellular acetic acid was obviously higher with ethyl acetate than without ethyl acetate. More acetic acid could provide more precursors for kitasamycin. The addition of ethyl acetate could meet the high demand for acetic acid, thereby increasing kitasamycin titers.

\section{Effects of ethyl acetate on the specific activity of enzymes}

To further determine the mechanism underlying high kitasamycin production, the specific activities of AS, AK, and APT were investigated in both conditions. AS and AK coupled with acylphosphotransferase are two enzymatic systems that supply acetyl-CoA for macrolide lactonic ring formation, leading to kitasamycin biosynthesis (KHAOUA et al., 1992). As shown in Figure 7(a), the specific activity of AS with ethyl acetate addition reached a maximum of $17.7 \mathrm{U} / \mathrm{mg}$ at $47 \mathrm{~h}$. The control showed a higher specific activity of $15.2 \mathrm{U} / \mathrm{mg}$ at $47 \mathrm{~h}$. Subsequently, acetyl-CoA activity in both cases declined rapidly, and from 78 to $112 \mathrm{~h}$, it remained relatively constant until the termination of fermentation. These results indicate that AS was primarily important during the early phase of kitasamycin biosynthesis.

Compared with the control, two peaks of AK specific activity emerged later in the fermentation period with the addition of ethyl acetate. There was no difference in $\mathrm{AK}$ specific activity between the ethyl acetate conditions and the control condition with respect to the first peak. However, the second peak for the ethyl acetate condition showed an AK specific activity of 765 $\mathrm{U} / \mathrm{mg}$ protein, which was significantly higher than that of the control (Figure 7(b)), indicating that more acetate was phosphorylated to generate acetylphosphate, which provided more substrates for the synthesis of acetyl-CoA.

The APT-specific activity curves for the two conditions showed a similar trend, with two peaks in the fermentation process. A peak of $22.4 \mathrm{U} / \mathrm{mg}$ in the APT specific activity emerged at $64 \mathrm{~h}$ and a second peak of $25.3 \mathrm{U} / \mathrm{mg}$ emerged at $88 \mathrm{~h}$ for the ethyl acetate treatment; both peaks were higher than those of the control (Figure 7(c)). These results indicate that the effect of APT was more remarkable in the middle and later periods, in which more acetyl-CoA was present to promote the biosynthesis of kitasamycin. 

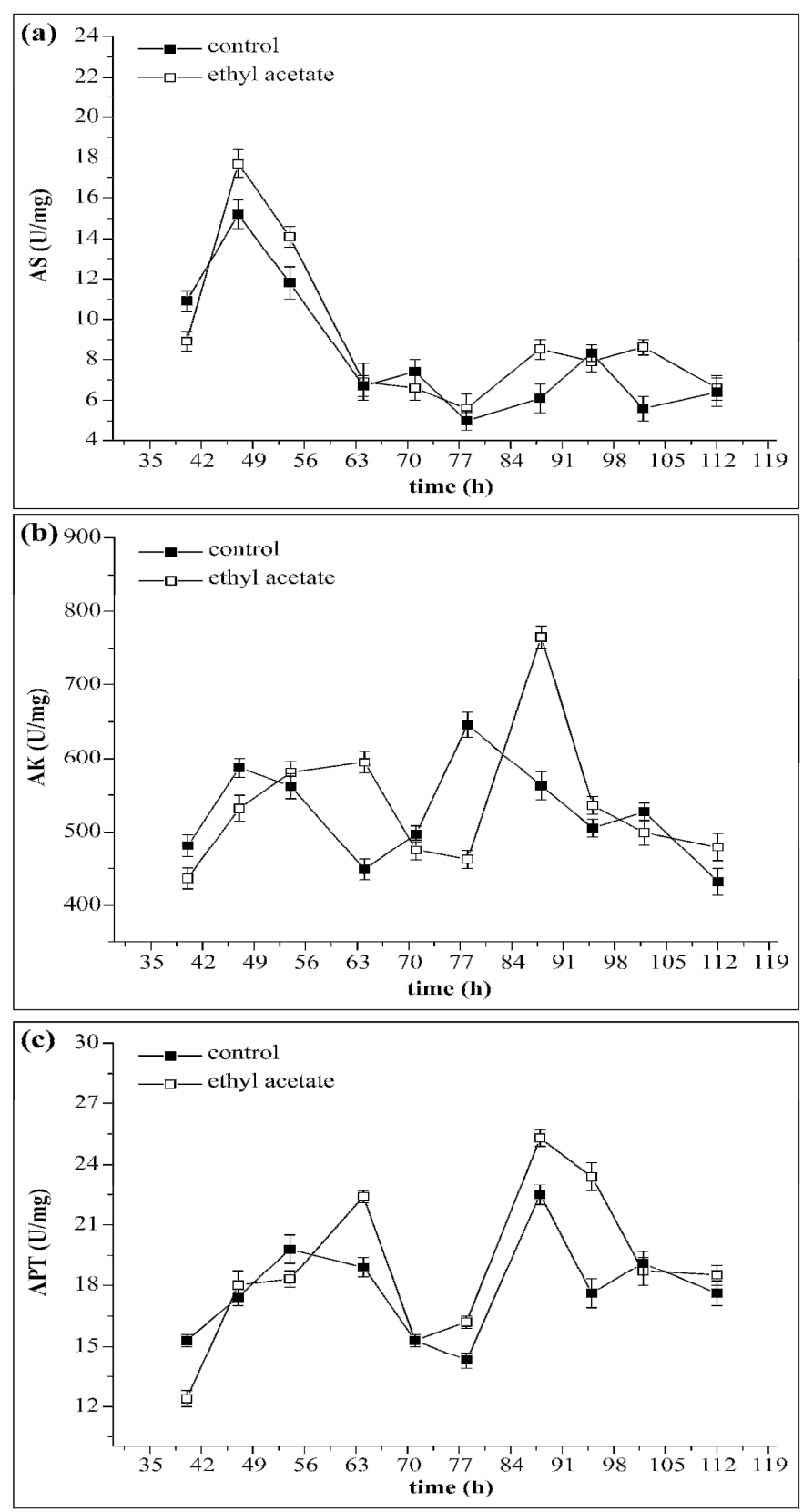

Figure 7. Influence of ethyl acetate on the specific activity of kitasamycin acetyl-CoA synthetase (a), acetate kinase (b), and acyl-phosphotransferase (c). Ethyl acetate ( $\square$ ) and control

\section{DISCUSSION}

Ethyl acetate was more effective than sodium acetate with respect to the enhancement of kitasamycin titers. When ethyl acetate was added, the kitasamycin titer increased by $21 \%$ and the $\mathrm{A}_{5}$ content increased by $5.1 \%$ in a 15 -L fermentor. The $\mathrm{A}_{5}$ fraction had the highest content and had extremely high antimicrobial activity among all main components of kitasamycin. The $\mathrm{A}_{5}$ component increased with supplementation of ethyl acetate, which resulted in remarkable advantages in the culture broth. However, the components of kitasamycin are various and complex, and the detailed pathways of $\mathrm{A}_{5}$ to $\mathrm{A}_{4}$ and relevant acetylation genes are not clear. Further studies should thus identify acetylation inhibitors of C-3 of the 16-membered lactone ring to optimize kitasamycin production. Inhibition of the expression of relevant acetylation genes for $\mathrm{A}_{5}$ to $\mathrm{A}_{4}$ might also enhance kitasamycin production (ZHENG; GAO, 2015).

Acetic acid and butyric acid are precursors for kitasamycin biosynthesis (OMURA et al., 1975). The addition of ethyl acetate not only supplied the precursors for kitasamycin biosynthesis but also induced the synthesis of AS, AK and APT, which activated short-chain fatty acids. The presumed 
function of AS, AK and APT was to increase the availability of acylthioesters C2, C3, C4 for aglycone synthesis, especially the increased $\mathrm{AK}$ and APT were made during the antibiotic production phase (KHAOUA et al., 1992), it was known from kitasamycin structure that aglycone was necessary parts for kitasamycin (OMURA et al., 1975). Our results show that $\mathrm{AS}, \mathrm{AK}$, and $\mathrm{APT}$ were all activated and enhanced the production of kitasamycin during the synthesis phase. As can be seen, the addition of $0.48 \%$ ethyl acetate as precursors in the medium at the beginning of cultivation was favorable to improve kitasamycin biosynthesis.

\section{CONCLUSION}

Overall, using ethyl acetate as precursor was a new strategy in the field of antibiotic biosynthesis. This slow decomposition of ethyl acetate has favorable practical value with respect to precursor addition and reduces the inhibitory effects of excessive precursors.

\section{ACKNOWLEDGMENTS}

This work was supported by Topfond Pharmaceutical Co., Ltd., Henan, China.

RESUMO: Para melhorar a biossíntese de kitasamicina por Streptomyces kitasatoensis Z-7, a adição de dois precursores, acetato de sódio e acetato de etila, ao meio de fermentação foi avaliada. O acetato de etila foi o precursor mais efetivo em comparação com as condições de controle; Em um fermentador de $15 \mathrm{~L}$, o título de kitasamicina foi $21 \%$ maior quando $0,48 \%$ de acetato de etila foi adicionado em comparação com as condições de controle. O conteúdo do componente A5 aumentou 5,1\%, e o conteúdo A4 diminuiu ligeiramente em comparação com o do controle. Durante a síntese de kitasamicina, as concentrações intracelulares e extracelulares de ácido acético foram maiores para S. kitasatoensis Z-7 suplementado com acetato de etila do que para a cepa não suplementada, e as atividades de acil-CoA sintetases, acil-fosfotransferases e acil-cinases também foram significativamente aumentadas, sugerindo que níveis aumentados de acetil-CoA podem explicar o alto título de kitasamicina. Esses achados podem melhorar a produção em escala industrial da kitasamicina para uso clínico, e a adição de $0,48 \%$ de acetato de etila como precursores no meio no início do cultivo foi um novo método para mitigar a influência negativa no crescimento celular do excesso de precursor.

PALAVRAS-CHAVES: Streptomyces kitasatoensis. Acetato etílico. Fermentação. Componente. Kitasamicina.

\section{REFERENCES}

CHAN, Y. A.; PODEVELS, A. M.; KEVANY, B. M.; THOMAS, M. G. Biosynthesis of polyketide synthase extender units. Natural Products Reports, v. 26, n. 1, p. 90-114, Jan 2009. https://doi.org/10.1039/B801658P

CHEN, Y.; HUANG, M.; WANG, Z.; CHU, J.; ZHUANG, Y.; ZHANG, S. Controlling the feed rate of glucose and propanol for the enhancement of erythromycin production and exploration of propanol metabolism fate by quantitative metabolic flux analysis. Bioprocess and Biosystems Engineering, v. 36, n. 10, p. 1445-1453, Oct 2013. https://doi.org/10.1007/s00449-013-0883-9

HATA, T.; SANO, Y.; OHKI, N.; YOKOYAMA, Y.; MATSUMAE, A.; ITO, S. Leucomycin, a new antibiotic. The Journal of Antibiotics, v. 6, p. 87-89, Apr 1953.

HOPWOOD, D. A. Genetic contributions to understanding polyketide synthases. Chemical Reviews, v. 97, n. 7, p. 2465-2498, Nov 1997. https://doi.org/10.1021/cr960034i

KHAOUA, S.; LEBRIHI, A.; LAAKEL, M.; SCHNEIDER, F.; GERMAIN, P., LEFEBVRE, G. Influence of short-chain fatty acids on the production of spiramycin by Streptomyces ambofaciens. Applied Microbiology and Biotechnology, v. 36, n. 6, p. 763-767, Mar 1992. https://doi.org/10.1007/BF00172190 
KITAO, C.; MIYAZAWA, J.; OMURA, S. Induction of the bioconversion of leucomycins by glucose and its regulation by butyrate. Agricultural and Biological Chemistry, v. 43, n. 4, p. 833-839, 1979.

https://doi.org/10.1271/bbb1961.43.833

https://doi.org/10.1080/00021369.1979.10863540

OMURA, S.; NAKAGAWA, A.; TAKESHIMA, H.; ATUSMI, K.; MIYAZAWA, J.; PIRIOU, F.; LUKACS, G. Letter: Biosynthetic studies using 13C enriched precursors on the 16-membered macrolide antibiotic leucomycin $A_{3}$. Journal of the American Chemical Society, v. 97, n. 22, p. 6600-6602, Oct 1975. https://doi.org/10.1021/ja00855a065

ROYCE, L. A.; LIU, P.; STEBBINS, M. J.; HANSON, B. C.; JARBOE, L. R. The damaging effects of short chain fatty acids on Escherichia coli membranes. Applied Microbiology and Biotechnology, v. 97, n. 18, p. 8317-8327, Sep 2013. https://doi.org/10.1007/s00253-013-5113-5

TAN, Z.; YOON, J. M.; NIELSEN, D. R.; SHANKS, J. V.; JARBOE, L. R. Membrane engineering via trans unsaturated fatty acids production improves Escherichia coli robustness and production of biorenewables. Metabolic Engineering, v. 35, p. 105-113, May 2016. https://doi.org/10.1016/j.ymben.2016.02.004

VANDERHAEGHE, H.; HOOGMARTENS, J. Macrolides, Chemistry, Pharmacology and Clinical Uses. Paris: Arnette Blackwell, 1993.

VÉZINA, C.; BOLDUC, C.; KUDELSKI, A.; AUDET, P. Biosynthesis of kitasamycin (leucomycin) by leucine analog-resistant mutants of Streptomyces kitasatoensis. Antimicrobial Agents and Chemotherapy, v. 15, n. 5, p. 738-746, May 1979. https://doi.org/10.1128/AAC.15.5.738

WOODWARD, R. B. Struktur und biogenese der makrolide. Angewandte Chemie, v. 69, n. 1-2, p. 50-58, Jan 1957. https://doi.org/10.1002/ange.19570690109

ZENG, J.; YE, R. F.; ZHENG, Y. T.; MAO Q. -G.; LV, H. P.; SHI, T. T. Strain screening and sodium lactate effect on spiramycin production in Streptomyces spiramyceticus. Research on Chemical Intermediates, v. 42, n. 3, p. 1627-1638, Mar 2016. https://doi.org/10.1007/s11164-015-2107-1

ZHENG, Q.; GAO, S. The effect of surfactant on fermentation of kitasamycin in Streptomyces kitasatoensis. Biotechnology and Applied Biochemistry, v. 63, n. 6, p. 895-900, Nov 2015.

https://doi.org/10.1002/bab.1443 